\title{
Atypical presentation of autoimmune hepatitis-primary sclerosing cholangitis overlap syndrome associated with hypereosinophilia: a case report and review of the literature
}

\author{
Behzad Hatami ${ }^{1}$, Hamide Rahmani Seraji ${ }^{2,4^{*}}$ (D) and Mohaddese fallahi ${ }^{3}$
}

\begin{abstract}
Background: Autoimmune hepatitis-primary sclerosing cholangitis overlap syndrome is a form of autoimmune hepatitis with cholestatic features and is characterized by negative anti-mitochondrial antibody and cholangiographic changes on magnetic resonance cholangiopancreatography or endoscopic retrograde cholangiopancreatography. Peripheral blood hypereosinophilia in conjunction with autoimmune hepatitis-primary sclerosing cholangitis overlap syndrome has not been reported yet. Here we present a case of autoimmune hepatitis-primary sclerosing cholangitis overlap syndrome with hypereosinophilia.
\end{abstract}

Case presentation: A 33-year-old Iranian man with the fatigue, jaundice, elevated liver enzymes and alkaline phosphatase, and hypereosinophilia was referred to our hospital. Viral and autoimmune hepatitis were excluded, and secondary workups for hypereosinophilia were all negative. Magnetic resonance cholangiopancreatography showed beaded appearance of intra- and extrahepatic biliary tree, and liver biopsy revealed interface hepatitis. Therefore, the diagnosis of autoimmune hepatitis-primary sclerosing cholangitis overlap syndrome was made, and prednisolone, azathioprine, and ursodeoxycholic acid was initiated. His jaundice and peripheral blood eosinophilia resolved after 2 weeks, and he became completely asymptomatic.

Conclusion: Eosinophils might contribute to the clinical presentation and disease complications.

Keywords: Autoimmune hepatitis, Primary sclerosing cholangitis, Overlap syndrome, Hypereosinophilia

\section{Background}

Autoimmune hepatitis-primary sclerosing cholangitis (AIH-PSC) overlap syndrome is a clinical, biochemical, immunological, and histological feature of $\mathrm{AIH}$ with cholangiographic abnormalities characteristic of PSC [1]. The frequency of the disease ranges from $1 \%$ to $6 \%$ [2] and is more common in males than females [1]. AIH or PSC concomitant with peripheral blood

*Correspondence: rahmaniseraji63.hr@gmail.com

2 Department of Hematology and Oncology, Shahid Beheshti University of Medical Sciences, Tehran, Iran

Full list of author information is available at the end of the article hypereosinophilia (HE) is a rare condition that has been described as case series [3-5], but to the best of our knowledge, peripheral blood hypereosinophilia in conjunction with AIH-PSC overlap syndrome has not been reported yet. Here we present a case of AIH-PSC overlap syndrome with hypereosinophilia.

\section{Case presentation}

A 33-year-old Iranian man was referred to our hospital because of fever, pruritus, jaundice, fatigue, dark urine, and pale stool for 3 months. He had no history of allergic disorder or recent travel. Medical history was unremarkable for gastrointestinal, liver, hematologic, or infectious original author(s) and the source, provide a link to the Creative Commons licence, and indicate if changes were made. The images or other third party material in this article are included in the article's Creative Commons licence, unless indicated otherwise in a credit line to the material. If material is not included in the article's Creative Commons licence and your intended use is not permitted by statutory regulation or exceeds the permitted use, you will need to obtain permission directly from the copyright holder. To view a copy of this licence, visit http://creativecommons.org/licenses/by/4.0/. The Creative Commons Public Domain Dedication waiver (http://creativeco mmons.org/publicdomain/zero/1.0/) applies to the data made available in this article, unless otherwise stated in a credit line to the data. 
disease. He had not used any medication. He was single and had no history of any high-risk sexual behavior. Family history was negative. On physical examination, sclera was icteric, and skin lesion, hepatosplenomegaly, lymphadenopathy, and ascites were not detected. The rest of the examinations were normal. In our hospital, laboratory data demonstrated a pattern of hypereosinophilia and hepatocellular liver injury: alanine transaminase (ALT) $710 \mathrm{IU} / \mathrm{L}$ (normal 10-40 IU/L), aspartate transaminase (AST) $389 \mathrm{IU} / \mathrm{L}$ (normal 5-40 IU/L), alkaline phosphatase (ALP) 677 IU/L (40 $130 \mathrm{IU} / \mathrm{L})$, gamma glutamyl transferase (GGT) $167 \mathrm{U} / \mathrm{L}(8-61 \mathrm{U} / \mathrm{L})$, total bilirubin $3.45 \mathrm{mg} / \mathrm{dl}(0.3-1.2 \mathrm{mg} / \mathrm{dl})$, direct bilirubin $2.79 \mathrm{mg} /$ $\mathrm{dl}(0-0.3 \mathrm{mg} / \mathrm{dl})$, prothrombin time (PT) 12.6 seconds, international normalized ratio (INR) $1.27(0.8-1.2)$. The complete blood count included: white blood cells (WBC) $15,630 / \mathrm{mm}^{3}$, hemoglobin $15.5 \mathrm{~g} / \mathrm{dl}$, platelets $152,000 /$ $\mathrm{mm}^{3}$, eosinophils $53 \%$, with absolute eosinophil count of $8283 / \mathrm{mm}^{3}$. Serum IgG level was $2200 \mathrm{mg} / \mathrm{dl}(700-$ $1400 \mathrm{mg} / \mathrm{dl})$. Serum IgG4 level was normal, and serum protein electrophoresis and immune fixation revealed polyclonal gammopathy. Infectious diseases were excluded by negative results for viral markers [hepatitis B surface antigen and hepatitis $C$ virus antibody, hepatitis $A$ virus antibody $(\operatorname{IgM})$, and anti-human immunodeficiency virus (HIV) antibody], serum antibodies to helminthic parasites, serologic test for Fasciola hepatica, and stool examinations for parasites and protozoa were all negative. Also, the workup for autoimmune hepatitis [antinuclear antibodies (ANA), smooth muscle antibody (SMA), anti-liver kidney microsomal type 1 (anti-LKM antibody 1) and anti-mitochondrial antibody (AMA)] was negative. Myeloproliferative diseases-related eosinophilia was excluded based on negative results for BCR-ABL P210 and P190 fusion transcript, JAK2 V617F mutation, Del [4] (q12q12)/FIP1L1PDGFRA, and PDGFRB/TEL. Bone marrow biopsy showed normal marrow hematopoiesis with increased morphologically normal eosinophils (account for $30 \%$ of all nucleated cells in bone marrow). Flow cytometry was normal as well. Abdominal ultrasonography and computed tomography scan of the abdomen and chest were unremarkable. Colonoscopy of the patient was normal. MRCP (Fig. 1) showed irregularity in the common hepatic duct (CHD) and common bile duct

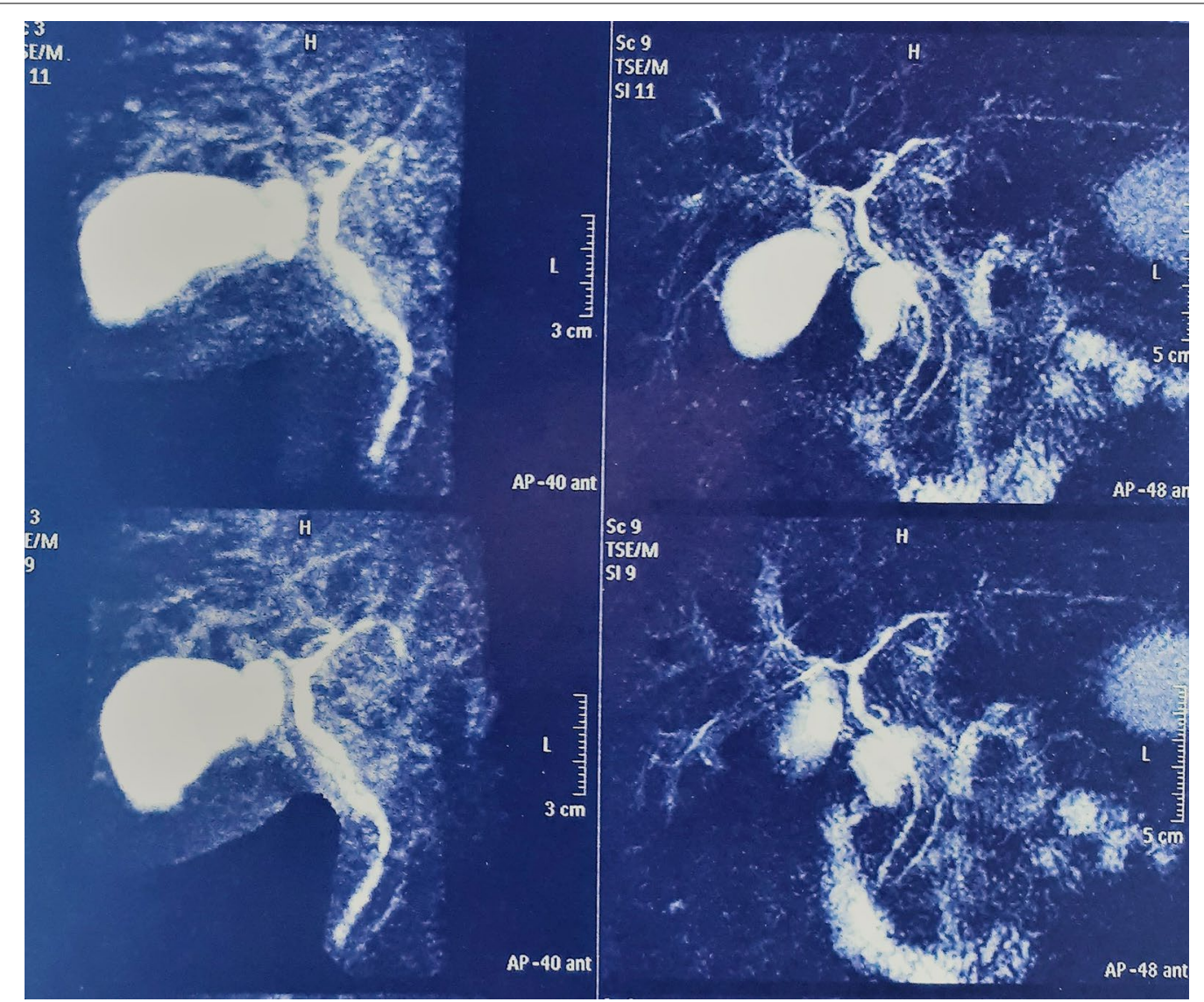

Fig. 1 Magnetic resonance cholangiopancreatography (MRCP) findings. MRCP at diagnosis showed irregularity in the CHD, CBD, and intrahepatic bile ducts with multiple strictures 

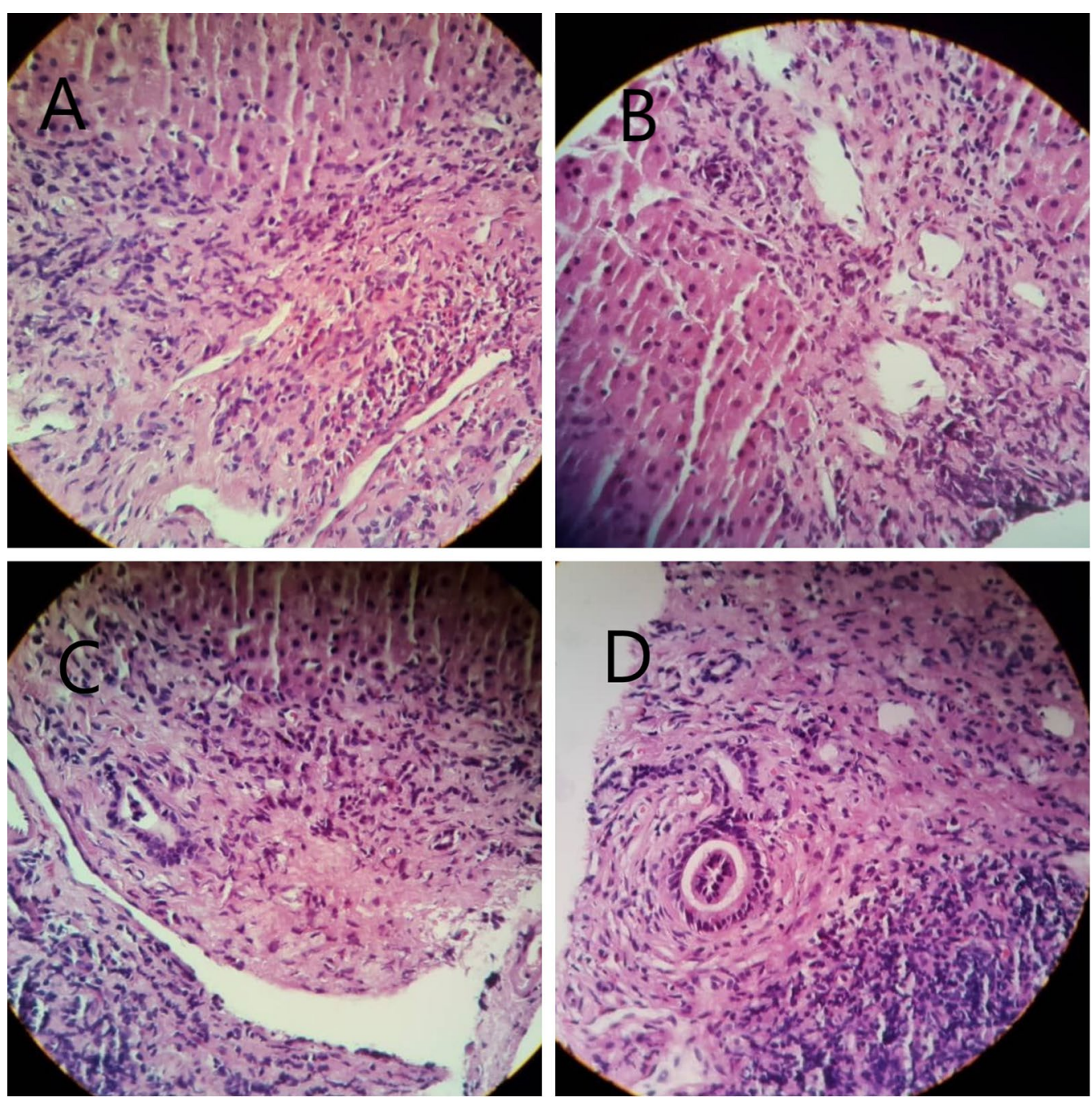

Fig. 2 Liver biopsy revealing moderate infiltration of lymphocytes, plasma cells, and eosinophils in portal area leading to interface hepatitis (A-C). Eosinophil infiltration (A) and lymphocyte and plasma cell infiltration in portal area (B, C). Mild fibrosis around bile ducts in onion-skin-like pattern was noted, but cholestasis and steatosis were not seen (D)

Table 1 Laboratory data of the patient at the time of diagnosis and 1, 6, and 12 months after initiation of treatment

\begin{tabular}{|c|c|c|c|c|}
\hline Laboratory data & At diagnosis & 1 month after treatment & 6 months after treatment & $\begin{array}{l}12 \text { months } \\
\text { after } \\
\text { diagnosis }\end{array}$ \\
\hline Total bilirubin (mg/dl) & 3.45 & 1.2 & 1.01 & 1.01 \\
\hline Direct bilirubin (mg/dl) & 2.79 & 0.2 & 0.2 & 0.2 \\
\hline AST (IU/L) & 710 & 35 & 30 & 30 \\
\hline ALT (IU/L) & 389 & 20 & 25 & 20 \\
\hline ALP (IU/L) & 677 & 100 & 67 & 65 \\
\hline GGT (U/L) & 167 & 54 & 60 & 60 \\
\hline WBC $\left(\right.$ per $\left.\mathrm{mm}^{3}\right)$ & 15,630 & 7000 & 5500 & 5000 \\
\hline Absolute eosinophil count (per $\mathrm{mm}^{3}$ ) & 8283 & 150 & 100 & 125 \\
\hline
\end{tabular}




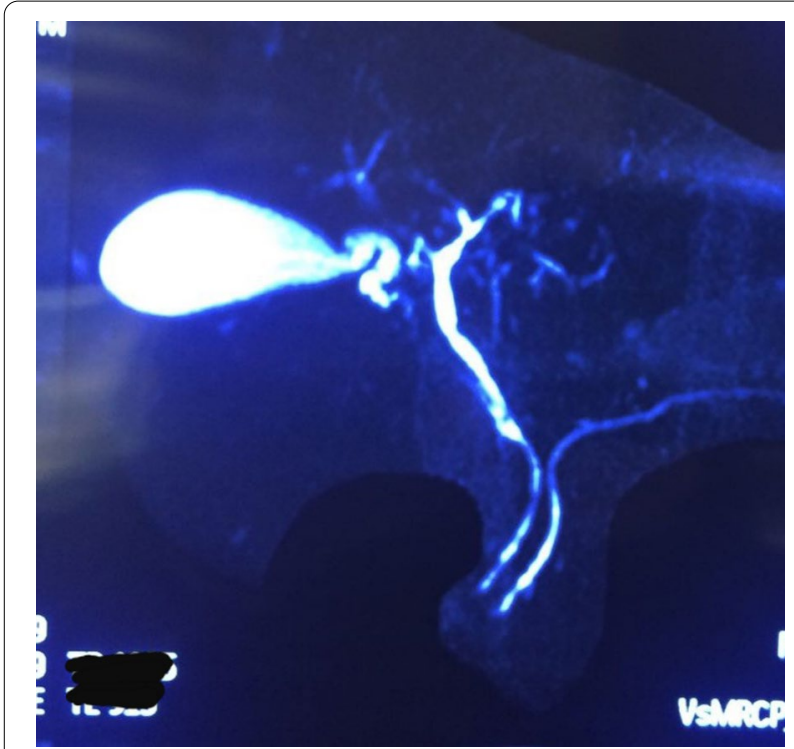

Fig. 3 Second MRCP of the patient after 6 months

(CBD) walls with multiple narrowing. Also, fine irregularity in the intrahepatic bile ducts with multiple strictures, beaded appearance, and some prominent lymph nodes in porta hepatis measuring up to $32 \times 13 \mathrm{~mm}$ size were seen. Liver biopsy was done for the patient and revealed moderate infiltration of lymphocytes, plasma cell, and eosinophils in the portal area leading to interface hepatitis and multiple focal and confluent necrosis. Bile duct proliferation was not seen. Mild fibrosis around bile ducts in onion-skin-like pattern was noted, but cholestasis and steatosis were not seen (Fig. 2).

The diagnosis of AIH-PSC overlap syndrome was made, and prednisolone $30 \mathrm{mg} /$ day, azathioprine $50 \mathrm{mg} /$ day, and ursodeoxycholic acid (UDCA) $300 \mathrm{mg}$ three times per day was commenced. Prednisolone was gradually tapered to $5 \mathrm{mg}$ during 2 months. His jaundice and peripheral blood eosinophilia resolved after 2 weeks, and he became completely asymptomatic. Table 1 presents laboratory data of the patient at the time of diagnosis and 1,6 , and 12 months after initiation of treatment. MRCP of the patient after 6 months showed intrahepatic bile ducts, CHD, and CBD luminal irregularity without dilation (Fig. 3).

\section{Discussion and conclusion}

AIH/PSC overlap syndrome is a form of AIH with cholestatic features and is characterized by negative AMA and cholangiographic changes on MRCP or ERCP $[6,7]$. Although eosinophilia is rarely reported in association with either AIH or PSC alone [8,9], there has been no report of eosinophilia in association with AIH/PSC overlap syndrome, to the best of our knowledge. In our case, irrespective of noticeable peripheral blood eosinophilia, we made the diagnosis of AIH/PSC based on the mixed pattern of elevated liver enzymes, hypergammaglobulinemia, beaded appearance of intra- and extrahepatic biliary tree on MRCP, and marked interface hepatitis in liver histopathology. On the other hand, due to HE, hypereosinophilic syndrome with hepatic involvement was also suggested.

Hypereosinophilia (HE) in the peripheral blood is defined as an absolute eosinophil count (AEC) $>1.5 \times 10 / \mathrm{L}$ (or $>1500$ cells $/ \mu \mathrm{L}$ ) on two examinations separated in time by at least 1 month, and hypereosinophilic syndrome (HES) is defined by the association of HE with eosinophil-mediated organ damage and/or dysfunction [10] that is classified into three categories. Primary (or neoplastic) HES occurs in the setting of an underlying stem cell, myeloid, or eosinophilic neoplasm, and was excluded in our case according to laboratory data and bone marrow biopsy (BMB) findings as mentioned above. Secondary (or reactive) HES was excluded based on negative results for allergies or parasitic infections and finally idiopathic HES in which the underlying cause of HE remains unknown despite a thorough etiologic workup. The last type of HES cannot be excluded for our patient, although he had AIH-PSC overlap syndrome as an underlying disease, but there is no evidence to confirm AIH-PSC overlap syndrome as the underlying cause of HE. Kawamura et al. summarized reports of liver injury associated with hypereosinophilia in ten cases of active hepatitis with HES. Common findings on liver biopsy of the participants were portal inflammation and infiltration of eosinophils in this area [11], similar to findings of liver biopsy in our patient. On the other hand, the presence of an onion-skin pattern, which is the most specific histologic finding in PSC, goes against the diagnosis of HES. PSC with HE and eosinophilic cholangiopathy are two different entities; it is sometimes difficult to distinguish between them, and most clinical evidence about them has come from case reports [12]. Ichikawa et al. presented a case of HES with PSC according to bile duct changes on endoscopic retrograde cholangiopancreatography (ERCP) that was treated with prednisolone and UDCA. Dramatic response to prednisolone was observed, and he was completely asymptomatic after 2 months [13]. In cases reported by Grauer et al. [8] and Schoonbroodt et al. [9], improvement of the bile duct lesion in repeated ERCP after treatment was established as well. Such a dramatic response to corticosteroid may suggest that the bile duct involvement of these patients was related to eosinophilia. In our case, symptoms (fever, pruritus, jaundice, fatigue, dark urine, and pale stool), 
liver function tests, and HE quickly improved after initiation of treatment with prednisolone, azathioprine, and UDCA. This may suggest that HE is involved in the pathogenesis of the disease, although the existence of bile duct changes on follow-up MRCP contradicts this. In conclusion, we here reported a case of AIH-PSC overlap syndrome associated with $\mathrm{HE}$ in which eosinophils might contribute to the clinical presentation and disease complications.

\section{Abbreviations \\ AlH-PSC: Autoimmune hepatitis-primary sclerosing cholangitis; HE: Hypere- osinophilia; MRCP: Magnetic resonance cholangiopancreatography; CHD: Common hepatic duct; CBD: Common bile duct.}

\section{Acknowledgements}

On behalf of all the authors, I acknowledge the contribution of Dr. Mojtaba Ghadiani to this article.

\section{Authors' contributions}

BH collected data and drafted and also revised the manuscript; HRS collected data and drafted the manuscript; MF advised on the pathological report of the study. This paper, including the abstract, was not previously published in any language, and it is not currently under consideration elsewhere for publication. All authors read and approved the final manuscript.

\section{Funding}

No funding

\section{Availability of data and materials}

The datasets used during the current study are available from the corresponding author on reasonable request.

\section{Declarations}

Ethics approval and consent to participate

The study was approved by Ethics Committee of Shahid Beheshti University of Medical Sciences, and all patient data will remain confidential.

\section{Consent for publication}

Written informed consent was obtained from the patient for publication of this case report and any accompanying images. A copy of the written consent is available for review by the Editor-in-Chief of this journal.

\section{Competing interests}

The authors declare that they have no competing interests.

\section{Author details}

${ }^{1}$ Gastroenterology and Liver Diseases Research Center, Research Institute for Gastroenterology and Liver Diseases, Shahid Beheshti University of Medical
Sciences, Tehran, Iran. ${ }^{2}$ Department of Hematology and Oncology, Shahid Beheshti University of Medical Sciences, Tehran, Iran. ${ }^{3}$ Department of Pathology, Shahid Beheshti University of Medical Sciences, Tehran, Iran. ${ }^{4}$ Department of Hematology and Oncology, Shahid Beheshti University of Medical Sciences, Tehran, Iran.

Received: 30 July 2020 Accepted: 31 Auqust 2021

Published online: 19 October 2021

References

1. Nayagam JS, Miquel R, Joshi D. Overlap syndrome with autoimmune hepatitis and primary sclerosing cholangitis. EMJ Hepatol. 2019;7(1):95-104.

2. Bairy l, et al. Autoimmune hepatitis—-primary biliary cirrhosis overlap syndrome. J Clin Diagn Res. 2017;11(7):07-9.

3. Kaya M, Angulo P, Lindor KD. Overlap of autoimmune hepatitis and primary sclerosing cholangitis: an evaluation of a modified scoring system. $J$ Hepatol. 2000;33:537.

4. van Buuren HR, van Hoogstraten HJE, Terkivatan T, et al. High prevalence of autoimmune hepatitis among patients with primary sclerosing cholangitis. J Hepatol. 2000;33:543.

5. Gohlke F, Lohse AW, Dienes HP, et al. Evidence for an overlap syndrome of autoimmune hepatitis and primary sclerosing cholangitis. J Hepatol. 1996;24:699.

6. McNair AN, Moloney M, Portmann BC, et al. Autoimmune hepatitis overlapping with primary sclerosing cholangitis in five cases. Am J Gastroenterol. 1998;93:777.

7. Gregorio GV, Portmann B, Karani J, et al. Autoimmune hepatitis/sclerosing cholangitis overlap syndrome in childhood: a 16-year prospective study. Hepatology. 2001;33:544.

8. Horiuchi K, et al. Marked eosinophilia as the first manifestation of sclerosing cholangitis. Intern Med. 2009;48:1377-82.

9. Chowdry S, Rubin E, Sass DA. Acute autoimmune hepatitis presenting with peripheral blood eosinophilia. Ann Hepatol. 2012;11:559-63.

10. Kawamura T, et al. A possible case of hepatitis due to hypereosinophilic syndrome. Intern Med. 2016;55:1453-8.

11. Perdigoto R, Carpenter HA, Czaja AJ. Frequency and significance of chronic ulcerative colitis in severe corticosteroid-treated autoimmune hepatitis. J Hepatol. 1992;14:325.

12 Fauci AS, Harley JD, Roberts WC, Ferrans VJ, Gralnick HR, Bjornson HB. The idiopathic hypereosinophilic syndrome. Clinical, pathophysiologic and therapeutic consideration. Ann Intern Med. 1982;97:78-92.

13. Ichikawa $\mathrm{N}$, et al. Sclerosing cholangitis associated with hypereosinophilic syndrome. Intern Med. 1997;36:561-4.

\section{Publisher's Note}

Springer Nature remains neutral with regard to jurisdictional claims in published maps and institutional affiliations.

\footnotetext{
Ready to submit your research? Choose BMC and benefit from:

- fast, convenient online submission

- thorough peer review by experienced researchers in your field

- rapid publication on acceptance

- support for research data, including large and complex data types

- gold Open Access which fosters wider collaboration and increased citations

- maximum visibility for your research: over 100M website views per year
}

At BMC, research is always in progress.

Learn more biomedcentral.com/submissions 